\title{
RECURRENCE OF HERNIA AFTER MESH HERNIOPLASTY - A STUDY OF 100 CASES
}

\author{
Hossain $\mathrm{SMS}^{1}$, Rahman $\mathrm{MM}^{2}$, Hasan $\mathrm{M}^{3}$
}

\begin{abstract}
Introduction: Recurrences have been a significant problem following hernia repair. Prosthetic materials are increasingly used in hernia repair to prevent recurrences. Their use has been associated with several advantages, such as less postoperative pain, rapid recovery and low recurrence rates.
\end{abstract}

Objectives: This study has been done to find out the early and late morbidity specially the recurrence rates of Hernia after mesh hernioplasty.

Methods: This retrospective study, was performed on 100 patients between the periods of October 2007 to October 2012 at Combined Military Hospital, Dhaka, on whom tension free open repair were performed by Rives (Inlay), Lichtenstein (onlay) or Stoppa (GPRVS) technique. Stoppa technique was applied in bilateral cases. Laparoscopic inguinal hernia repair was done by TAPP (Trans Abdominal Pre Peritoneal) approach. All data concerning age, sex, history, and symptoms of patients, as well as the post operative condition of the patients were recorded in predesigned data sheet.

Results: Out of 100 cases 90 (90\%) were male and $10(10 \%)$ were female. The overall age ranged between $30-80$ years with an increased incidence between 5 th and 6 th decades $(50 \%)$. Most of the patients were having inguinal Hernia $(75 \%)$, followed by incisional hernia in 15 (15\%) and paraumbilical hernia in $10(10 \%)$ patients. Among inguinal hernia, direct variety were $53(58.2 \%)$, indirect $29(31.9 \%)$, recurrent $9(9.9 \%)$, right sided $44(48.3 \%)$, left sided $31(34.1 \%)$ and bilateral 16 $(17.6 \%)$. Fifteen (15\%) cases had diabetes mellitus, $10(10 \%)$ cases had hypertension, $12(12 \%)$ cases had been suffering from bronchial asthma and 2 $(2 \%)$ cases had features of prostatism. Ninety two $(92 \%)$ patients underwent open surgery and $8(8 \%)$ cases laparoscopic hernioplasty. Among the open procedure done (83 procedures) in inguinal hernias unilateral inlay inguinal hernioplasty (Rives) was done in $47(56.6 \%)$, onlay (Lichtenstein) in 20 $(24.1 \%)$ and Stoppa procedure was done in 16 (19.3\%) bilateral cases. In all 100 cases, a sheet of Polypropyelene mesh was given as prosthetic material. Post operatively a few patients developed complication. Ecchymosis of skin in $2(2 \%)$, testicular swelling and orchitis in $4(4 \%)$, wound infection in $3(3 \%)$, retention of urine in $10(10 \%)$ cases. All were treated and improved. $2(2 \%)$ cases developed recurrence after operation as found in follow-up where onlay mesh were given and who had features of prostatism.

Conclusion: Tension-free mesh hernia repair is a simple, safe, comfortable and effective method, with extremely low early and late morbidity and remarkably low recurrence rate and therefore it is a preferred method for hernia repair.

1. Lt Col S.M. Shakhwat Hossain, MBBS, FCPS, D.HBS (China), Graded Specialist in Surgery, CMH, Dhaka;

2. Col Md. Mahbubur Rahman, MBBS, FCPS, Fellow Colorectal Surgery (France), Professor of Surgery, AFMC, Dhaka; 3. Lt Col Masroor Hasan, MBBS, FCPS, MS (Plastic Surgery), Graded Specialist in Surgery, CMH, Ctg. 
Key-words: Hernia, Prolene mesh, Inlay, Onlay, Recurrence.

\section{Introduction}

The surgical history of inguinal hernias dates back to ancient Egypt. From Bassini's heralding of the modern era to today's mesh-based open and laparoscopic repairs, this history parallels closely the evolution in anatomical understanding and development of the techniques of general surgery ${ }^{1}$.Accounting for $75 \%$ of all abdominal wall hernias, and with a lifetime risk of $27 \%$ in men and $3 \%$ in women, inguinal hernia repair is one of the most commonly performed surgeries in the world ${ }^{2}$. In the United States, inguinal herniorrhaphy accounts for approximately 800,000 cases yearly ${ }^{3}$. The lifetime risk rate of inguinal hernia is $25 \%$ in males and $2 \%$ in females ${ }^{4}$. The risk of inguinal hernia increases with age, and the annual incidence is around $50 \%$ by the age of $75^{5}$. Approximately two-thirds of inguinal hernias are indirect, and one third is direct ${ }^{6}$. For many decades, patients underwent the traditional tissue approximation repair. In a Cochrane review comparing mesh to nonmesh open repair, evidence was sufficient to conclude that the use of mesh was associated with a reduced rate of recurrence ${ }^{3}$. An incisional hernia develops in $3-13 \%$ of laparotomy incision ${ }^{7}$. Unfortunately, primary repair of incisional hernias often yield un-satisfactory results; reported recurrence rates have ranged from $25-52 \%{ }^{8,9}$. Similarly no consensus on the best techniques for the repair of paraumbilical hernia in adult is present ${ }^{10}$. Recently, open and laparoscopic tension free mesh hernioplasty procedures have widely replaced the tissue approximation repair.

\section{Materials and Methods}

This study inchudes 100 cases of hernias, treated in the department of surgery, Combined Military Hospital, Dhaka Cantonment during the period of October 2007 to October 2012. Detailed history was taken with special emphasis on previous operation, medical conditions such as bronchial asthma, diabetes mellitus, hypertension, constipation, difficulty in micturition.
The patients were investigated thoroughly to exclude predisposing factor that may require operative treatment in near future. All the patients underwent surgery. They were positioned supine on operation table. In some cases a catheter was inserted to decompress the bladder. Gastric decompression was accomplished by placement of a naso-gastric tube in few cases. Access to the abdomen was obtained by means of an open technique in 92 cases and laparoscopic technique in the reminder. The hernia sac contents were reduced, but the peritoneal sac itself was left in situ. Dissection was carried out in most of the cases under fascia transversalis (inlay) and in a few cases over transversalis fascia (onlay). Prolene mesh was positioned and secured by nonabsorbable suture. In most of the cases of inguinal hernia, posterior wall of inguinal canal was strenghtened by Bassini method with non absobable suture. After that wounds were closed in layers.

\section{Result}

The total number of patients was 100 . Of them $90(90 \%)$ were male and $10(10 \%)$ were female with a ratio of 9:1. Table-I shows the age ranging from 30 years to 80 years with increasing incidence between 5th and 6th decades. Table-II shows location of different types of hernias where inguinal hernia are found in $75(75 \%)$ cases, incisional hernia in $15(15 \%)$ cases and paraumbilical hernia in $10(10 \%)$ cases. Table-III shows that direct inguinal hernia were maximum in number i.e. in $53(58.2 \%)$ cases, there after indirect inguinal hernia were found in $29(31.9 \%)$ cases and recurrent inguinal hernia in $9(9.9 \%)$ cases. Table-IV shows the procedure of prosthetic repair; polypropyelene mesh was applied on preperitoneal space i.e. Rives (Inlay) method in $60(65.5 \%)$ cases followed by Lichtenstein (Onlay) in 15(16.5\%) and stoppa (GPRVS) in 16(17.6\%) cases. Table-V shows the post operative complications; ecchymosis of skin in $2(2 \%)$ patients, testicular swelling in $4(4 \%)$, wound infection in $3(3 \%)$, retention of urine in $10(10 \%)$ and recurrence in $2(2 \%)$ cases. Table-VI shows the final outcome of the treatment. In our study 98 patients were completely cured. Two patients developed recurrence after hernioplasty where onlay hernioplasty was done and patients had features of prostatism. 
Table-I: Age distribution in patients of operated group $(n=100)$.

\begin{tabular}{|l|c|c|}
\hline Age in years & $\begin{array}{c}\text { No of } \\
\text { cases }\end{array}$ & Percentage \\
\hline 30 & 2 & 2 \\
\hline $31-40$ & 10 & 10 \\
\hline $41-50$ & 15 & 15 \\
\hline $51-60$ & 50 & 50 \\
\hline $61-70$ & 18 & 18 \\
\hline $71-80$ & 5 & 5 \\
\hline
\end{tabular}

Range $=30-80 \mathrm{yrs}$

Mean Age: 53.5 yrs

Increasing incidence between 5th and 6th decades

Table-II: Location of hernia $(n=100)$.

\begin{tabular}{|l|c|c|}
\hline Location & No of cases & Percentage \\
\hline Inguinal & 75 & 75 \\
\hline Incisional & 15 & 15 \\
\hline Paraumbilical & 10 & 10 \\
\hline
\end{tabular}

Table-III: Types of inguinal hernia $(n=91)$.

\begin{tabular}{|l|c|c|}
\hline Types & No of cases & Percentage \\
\hline Direct & 53 & 58.2 \\
\hline Indirect & 29 & 31.9 \\
\hline Recurrent & 9 & 9.9 \\
\hline
\end{tabular}

Table-IV: Procedure of prosthetic repair $(n=116)$.

\begin{tabular}{|l|c|c|}
\hline Procedure & No of cases & Percentage \\
\hline Rives (Inlay) & 47 & 40.5 \\
\hline Lichtenstein (Onlay) & 20 & 17.24 \\
\hline Stoppa (GPRVS) & 16 & 13.8 \\
\hline TAPP & 8 & 6.9 \\
\hline Inlay Mesh in Incisional Hernia & 15 & 12.9 \\
\hline Inlay Mesh in paraumbilical Hernia & 10 & 8.6 \\
\hline
\end{tabular}

Table-V: Post operative complication $(n=100)$.

\begin{tabular}{|l|c|c|}
\hline Complication & No of cases & Percentage \\
\hline Ecchymosis of skin & 2 & 2 \\
\hline Testicular Swelling/ Orchitis & 4 & 4 \\
\hline Wound infection & 3 & 3 \\
\hline Retention of urine & 10 & 10 \\
\hline Recurrence & 2 & 2 \\
\hline
\end{tabular}

Table-VI: Final outcome after operation $(n=100)$

\begin{tabular}{|l|c|c|}
\hline Result & No of cases & Percentage \\
\hline Complete cure & 98 & 98 \\
\hline Recurrence & 2 & 2 \\
\hline
\end{tabular}

\section{Discussion}

The true incidence of inguinal hernia is not known, although fairly accurate estimates are available, based on different survey ${ }^{11}$. The overall incidence in adults in western hemisphere varies between $10-15 \%{ }^{11}$. The incidence in our country is not known. The male to female ratio is similar to our study $^{11}$. The repair of these hernias represent as challenging surgical problem. Because primary repair with suture alone can yield failure rates of $10 \%$ to $30 \%{ }^{11}$. A variety of open and laparoscopic techniques using prosthetic mesh have been developed. Placement of mesh has been shown to reduce long term failure rate to $11 \%$ to $21 \%^{8}$. In our study, the recurrence rate is $2 \%$ during a mean follow-up time of 24 months. This correlates with other studies ${ }^{9}$.

In our study it is evident that inlay hernioplasty has better result than onlay hernioplasty. Post-operative recovery was uneventful in most of the cases except a few who developed minor complications after undergoing open surgical hernioplasty. These patients were later treated and they got improved. Laparoscopic surgical approaches have several advantages over traditional open operations, including reduction in hospital stay, post-operative pain and time required for convalescence. The increasing interest in minimally invasive surgery has encouraged development of techniques for performing hernia repair laparoscopically. Overall long term result of laparoscopic hernia repair is expected to be better than conventional mesh repair.

\section{Conclusion}

A decline in muscle strength and walking ability was evident after conventional hernia repair but not after mesh hernioplasty specially after laparoscopic hernioplasty. With careful patient and procedure selection, surgery is associated with less morbidity and thereby improves quality of life. This procedure is safe, well tolerated and well accepted by the patients. 


\section{References}

1. Lau WY. History of treatment of groin hernia. World J Surg. Jun 2002; 26(6):748-59.

2. Awad SS, Fagan SP. Current approaches to inguinal hernia repair. Am J Surg. Dec 2004; 188(6A Suppl):9S-16S.

3. Scott NW, McCormack K, Graham P, Go PM, Ross SJ, Grant AM. Open mesh versus non-mesh for repair of femoral and inguinal hernia. Cochrane Database Syst Rev. 2002; CD002197.

4. Nicks BA, Askew K. Hernias. In: eMedicine [Internet]. Omaha (NE): eMedicine.com; 2010 Jan 25 [accessed $2010 \mathrm{Jul} 14$ ].

5. Inguinal hernia: epidemiology. [Internet]. San Mateo (CA): Epocrates, Inc.; 2010 [accessed 2010 Jul 14]. [1 p].

6. Nicks BA, Askew K. Hernias. In: eMedicine [Internet]. Omaha (NE): eMedicine.com; 2010 Jan 25 [accessed $2010 \mathrm{Jul} 14$ ] .
7. Park A, Birch DW, Lovrics P. Laparoscopic and open incisional hernia repair : a comparison study. Surgery $1998 ; 124: 816-822$.

8. Lichtenstein IL, Shulman AG, Amid PK. The tension free hernioplasty. Am J surg $1989 ; 157$ : 188-193.

9. Wantz GE. Preperitoneal hernioplasty with unilateral giant prosthetic reinforcement of the visceral sac. Contemp Surg, 1994; 44 :83-89.

10. Lau $\mathrm{H}$, patil WG. Umbilical hernia in adult. Department of Surgery, University of Hong Kong Medical Centre, Tung wah Hospital, HongKong. Surg Endosc, 2003: 2016-2020.

11. Seymour I, Schwart $Z$ and Ellis H. Maingot's Abdominal operations. 9th ed. USA : Jack Abrahamson; 1990:215-296. 